\title{
The Role of Religious Coping in Perception of Suffering among Patients Undergoing Dialysis
}

\author{
Zahra Nikmanesh,,", and Samane Azaraein ${ }^{1}$ \\ ${ }^{1}$ Department of Psychology, University of Sistan and Baluchestan, Zahedan, Iran \\ "Corresponding author: Zahra Nikmanesh, Department of Psychology, Faculty of Education and Psychology, University of Sistan and Baluchestan, Zahedan, Iran. Tel: \\ +98-9151404553, E-mail: zahranikmanesh@yahoo.com
}

Received 2016 June 15; Revised 2016 September 16; Accepted 2016 September 25.

\begin{abstract}
Background: Chronic kidney disease is a threatening condition for the health, economic and social status of the affected person, his/her family and society.

Objective: With regard to the mental and health issues that patients undergoing dialysis encounter, the current study aimed to examine the role of religious coping in perception of suffering among these patients.

Methods: The current correlational study had a statistical population including all patients undergoing dialysis referred to Aliibn-Abi-Talib (AS) hospital in Zahedan, Iran, in 2015. The sample included 50 individuals selected using the convenience sampling method. To collect data, the perception of suffering scale and the religious coping scale were used and the obtained data was analyzed using the Pearson correlation coefficient and stepwise regression analysis via SPSS.

Results: The correlation results showed that religious activities (a dimension of religious coping) and psychological suffering (a dimension of perception of suffering) were significantly and inversely correlated $(\mathrm{P}<0.01)$. Moreover, the results indicated that religious activities (a dimension of religious coping) could predict 0.09 of the variance in psychological pain (a dimension of perception of suffering).

Conclusions: The increase in religious and spiritual activities can lead to a decrease in psychological pain among patients undergoing dialysis.
\end{abstract}

Keywords: Dialysis, Patients, Pain, Religion

\section{Background}

Chronic kidney failure is a life threatening condition that $2 \%$ to $3 \%$ of people deal with it worldwide. This failure leads to an irreversible loss of kidney function and kidney diseases and patients should be dependent on kidney replacement therapies for the rest of their lives (hemodialysis, peritoneal dialysis and kidney transplant) to prevent uremia and its complications (1). Disorders are caused as a result of the chronic kidney failure and the complications of hemodialysis make life very difficult for such patients and they should face many challenges to reach an acceptable level of health and physical, mental and social functioning (2). One of the most prevalent issues among patients undergoing hemodialysis is chronic pain. More than $50 \%$ of patients with kidney diseases and nearly $54 \%$ of patients undergoing hemodialysis have moderate to severe levels of chronic pain (3).

Pain is an unpleasant feeling and emotional experience perceived by people as a consequence of physical health problems such as injuries and diseases or as an implication of mental conditions caused by emotional factors (4). To cope with pain and complications, people usu- ally try to understand, explain and interpret it, attempt to overcome the complication and interpret it (5). In hard times, religion plays a role as a potential source of comfort and conformity (6).

Spirituality helps people to overcome the issues that they face and offers an optimistic and a hopeful outlook through creating a sense of purpose and meaning and integrating people's mental states (7). Pargament defined religion as a kind of religious coping. Religious coping is an internal source, which helps people to search for a meaning at the time of injury and creates intimacy with God, helps people to perceive the meaning of life, and leads to mental comfort (8). Spirituality increases patients' awareness, helps them to pay more attention to unknown aspects of life and to refine their thoughts, and helps patients to focus on the problem and on the method of dealing with it (9). Krause, in a study, indicated that suffering makes people aware of the existence of God and this is why people apply religion/spirituality as a way to deal with their pain and complications (10).

In recent years, health psychology paid great attention to the role of people's coping strategies and lifestyles in their levels of mental health. In this regard, religious cop- 
ing was defined as a method that uses religious resources including prayer and trust in and appeal to God to deal with stress (11). Tykockit, in a study, showed that perception of suffering in patients with Parkinson disease was significantly lower than that of the patients with other diseases (12). Investigating the impacts of religious coping on quality of life among patients with cancer also received a lot of attention and the overall results demonstrated that quality of life among religious people improved (13). Zeilani demonstrated that patients' religious beliefs and prayers, as religious activities, helped patients to experience lower levels of suffering. Religious-spiritual coping can be very helpful when dealing with chronic diseases (14). Ramirez showed that the positive religious coping was related to psychological health and quality of life in patients undergoing hemodialysis (15). Dedeli indicated that people apply cognitive and behavioral strategies including religion/ spirituality to cope with pain (16). Akbari demonstrated that religion creates hopefulness, compensates for negativism and increases happiness in people. In fact, religion gives meaning to people's life and death, and as a result creates an inner peace and reduces suffering in people (17). Another study showed a significant and positive relationship between religious beliefs and pain reduction (18). Beiranvand concluded that religious and spiritual interventions, including prayer and meditation, can be applied as a non-pharmaceutical pain management technique to reduce pain and increase calmness after a C-section (19). Ursaru indicated the importance of religious coping in patients with breast cancer (20). The results of a study carried out by Han showed that religious tendencies can reduce people's pain and suffering (21). Saltarlei demonstrated that pain perception and religion were correlated and the need to approach a religious phenomenon is of significant importance for pain management (22). Moreover, Salehi reported that religious attitudes were related to stress, depression and complications caused as a result of various diseases (23).

Although, many studies are conducted on investigating positive effects of religion and spirituality on various aspects of health in patients with chronic diseases, few studies are conducted on religious coping and almost no studies are carried out to examine different effects of the positive and negative religious copings on patients undergoing dialysis.

On the other hand, patients undergoing dialysis should deal with both daily life stress and stress resulting from unpredictable symptoms. Several symptoms, including disability, depression, insomnia, extreme irritability, anxiety and inability to cope with stress, are common among patients undergoing hemodialysis who experience pain. The experience of pain accompanies by various neg- ative and chronic effects. Different pharmaceutical and non-pharmaceutical methods are applied as pain relief methods. Given that pharmaceutical methods of relieving pain have many side effects and since several studies showed that suffering in patients with chronic pain may disrupt their daily functioning (14), safer methods with less complication should be sought in order to help patients to endure lower levels of pain. In this regard, the present study aimed to answer the following question: Do non-pharmaceutical methods, like the positive and negative religious copings, affect the level of pain in patients with kidney diseases?

\section{Objectives}

Since very few studies are conducted to examine the role of religious coping in perception of suffering, the present study aimed to determine the role of religious coping in perception of suffering among patients undergoing dialysis.

\section{Methods}

\subsection{Research Environment and Patients}

The current study employed descriptive-correlational method to predict the criterion variable. The predictor variable was religious coping and the criterion variable was the perception of suffering. The statistical population included all patients undergoing dialysis referred to Ali-ibn-Abi-Talib (AS) hospital in Zahedan, Iran, in 2015. The sample was selected using the convenience sampling method. Based on the results, 50 participants were selected (with a confidence interval [CI] of $95 \%$ and test power of $80 \%$ ).

To collect data, the patients willing to participate in this study, were asked individually to complete the questionnaire. The questionnaires were read to the illiterate patients and the selected responses by these patients were marked. All subjects expressed their consent to participate in the study.

Inclusion criteria were being 18 years old or older, having (at least) contradictory with acceptable understanding of Persian language, undergoing hemodialysis two or three times a week lasting for three to four hours, and not dealing with any psychological disorders. Exclusion criteria were all conditions that prevented the continuation of the study (i e, physical and mental crises) and hospitalization due to an acute disease. None of the samples were excluded from the study. 


\subsection{Questionnaires}

Two questionnaires on perception of suffering and religious coping were used to collect data.

\subsubsection{The experience and perception of suffering scale}

This scale was developed by Schulz et al. and measures three dimensions of suffering including physical, psychological and existential-spiritual suffering. The dimension of physical suffering includes nine items and two parts. In the first part, subjects are asked to indicate how much they experienced the mentioned symptoms in the last seven days and in the second part, subjects are asked to demonstrate how much each mentioned symptom was upsetting and stressful. Subjects can choose their answers based on a 4-point Likert scale ranging from never to always. In the physical dimension, the minimum score is 0 and the maximum 27.

The dimension of psychological suffering contains 15 items. In the items on psychological suffering, subjects are asked to indicate how often they experienced the listed excitements in the last seven days. Subjects can choose an answer ranging from never to always. In the psychological dimension, the minimum score is 0 and the maximum 45 .

In addition, existential-spiritual suffering is measured through applying nine items. The subjects are asked to indicate to what extent the statements related to their feelings in the last seven days are true and they can choose an answer ranging from never to always. In the existentialspiritual suffering dimension, the minimum score is 0 and the maximum 27.

The reliability of this scale was examined and confirmed by Schulz in three groups of African-Americans (physical 0.63, psychological 0.9 and existential-spiritual 0.86 ), white people (physical 0.43 , psychological 0.87 and existential-spiritual 0.84), and Spanish people (physical 0.6, psychological 0.85 and existential-spiritual 0.83) (24). In a study on patients with HIV, the Cronbach's alpha coefficients of physical suffering, psychological suffering and existential-spiritual suffering were $0.71,0.84$ and 0.81 , respectively. In the current study, the Cronbach's alpha coefficients of physical suffering, psychological suffering and existential-spiritual suffering were $0.79,0.84$ and 0.81 , respectively (25).

\subsubsection{Religious Coping Scale}

This scale was developed by Aflakseir and Coleman. This scale evaluates religious activities (six items, its score ranges from 0 to 24), negative feelings towards God (four items, its score ranges from 0 to16), benevolent reappraisal (six items, its score ranges from 0 to 24), passive religious coping (three items, its score ranges from 0 to 12) and active religious coping (three items, its score ranges from 0 to 12). The items are scored based on a 5-point Likert-type scale ranging from never $=0$ to always $=4$.

The positive religious coping includes three subscales, i e, religious activities, benevolent reappraisal and active religious coping. Thus, the minimum score is 0 and the maximum 60 for the positive religious coping. The negative religious coping includes negative feelings towards God and passive religious coping. Thus, the minimum score is 0 and the maximum score 48 for the negative religious coping.

The Cronbach's alpha coefficients of the reliability of religious activities, benevolent appraisal, negative feelings towards God, passive coping and active coping were 0.89 , $0.79,0.79,0.72$ and 0.79 , respectively (26). In another study, Cronbach's alpha coefficients of religious activities, benevolent appraisal, negative feelings towards God, passive coping and active coping were $0.71,0.72,0.71,0.74$ and 0.70 , respectively (27). In the current study, the Cronbach's alpha coefficients of religious activities, benevolent appraisal, negative feelings towards God, passive coping and active coping were $0.68,0.65,0.58,0.55$ and 0.82 , respectively.

\subsection{Ethical Consideration}

The protocol of the study (CT-18667) was reviewed and approved by the department of psychology at University of Sistan and Baluchistan in Zahedan, Iran. The main objectives and protocols of the study were explained to the participants. They were assured of the confidentiality of the collected information and freedom to withdraw from the study at any time during the study. Informed consents were obtained from all the participants.

Afterwards, the questionnaires were distributed among the patients. Whenever a question seemed vague, some additional explanations were also provided. It should be noted that these explanations were provided to avoid any kinds of ambiguity and/or bias.

\subsection{Statistical Analysis}

The Kolmogorov-Smirnov test was used to investigate the assumptions of parametric statistical tests and the results indicated that the levels of normal assumption for all dimensions of perception of suffering and religious coping were all greater than $\mathrm{P} \leq 0.05$. Therefore, the null hypothesis of normality of data was not rejected. This means that the data were normal.

The obtained data was analyzed using the Pearson correlation coefficient and regression analysis via SPSS ver. 19 . The Pearson correlation coefficient was used to probe the relationship between religious coping and perception of suffering and stepwise regression analysis was conducted 
to examine the role of religious coping to predict perception of suffering among the reliability of dialysis. Level of statistical significance was $\mathrm{P}<0.05$. Missing data were not included in the analyses.

\section{Results}

According to the obtained results (Table 1), $52 \%$ of the subjects were male ( 26 individuals) and $48 \%$ of them were female (24 individuals). Moreover, $32 \%$ of the subjects were single (16 individuals) and 68\% married (34 individuals) and the highest frequency was related to the age group of 45 to 55 years old $(28 \%)$. Considering their level of education, $28 \%$ of the subjects were illiterate, $22 \%$ of them finished the elementary school, $16 \%$ of them finished middle school, $22 \%$ of them had a high school diploma and $12 \%$ of them had a bachelor's degree.

Table 1. Demographic Data of the Study Subjects

\begin{tabular}{l|c|c|c}
\hline \multirow{4}{*}{ Education } & Variable & Frequency & Percent \\
\hline & Illiterate & 14 & 28 \\
\cline { 2 - 4 } & Elementary school & 11 & 22 \\
\cline { 2 - 4 } & Middle school & 8 & 16 \\
\cline { 2 - 4 } & High School & 17 & 34 \\
\cline { 2 - 4 } & Diploma and higher & & \\
\hline \multirow{4}{*}{ Marital status } & Single & 16 & 32 \\
\hline \multirow{4}{*}{ Gender } & Married & 34 & 68 \\
\hline \multirow{4}{*}{ Age, y } & Male & 26 & 52 \\
\cline { 2 - 4 } & Female & 24 & 48 \\
\hline \multirow{2}{*}{ Total } & $12-27$ & 16 & 32 \\
\hline & $28-43$ & 9 & 18 \\
\cline { 2 - 4 } & $44-59$ & 50 & 32 \\
\cline { 2 - 4 } & & & 16 \\
\hline
\end{tabular}

The descriptive data (Table 2) indicated that the means of physical suffering, psychological suffering, and existential/spiritual suffering were $7.02,12.56$ and 14 , out of maximums of 27, 45 and 27, respectively. These results showed that existential/spiritual suffering had the highest mean.

The results (Table 3 ) also showed that the means of all dimensions of the positive religious coping were greater than the average score of the questionnaire. Moreover, the means of all dimensions of the negative religious coping were lower than the average score of the questionnaire.

The results of the Pearson correlation coefficient indicated that religious activities (a dimension of religious
Table 2. The Means and Standard Deviations of Dimensions of Suffering among Study Subjects ${ }^{\mathrm{a}}$

\begin{tabular}{l|c|c|c}
\hline Variables & Dimensions & Mean & $\begin{array}{c}\text { Standard } \\
\text { Deviation }\end{array}$ \\
\hline \multirow{2}{*}{$\begin{array}{l}\text { Perception of } \\
\text { suffering }\end{array}$} & Physical suffering & 7.02 & 5.87 \\
\cline { 2 - 4 } & $\begin{array}{c}\text { Psychological } \\
\text { suffering }\end{array}$ & 12.56 & 6.77 \\
\cline { 2 - 4 } & $\begin{array}{c}\text { Existential/spiritual } \\
\text { suffering }\end{array}$ & 14.92 & 5.01 \\
\hline
\end{tabular}

${ }^{\mathrm{a}} \mathrm{N}=50$.

Table 3. The Means and Standard Deviations of Dimensions of Religious Coping among Study Subjects ${ }^{\mathrm{a}}$

\begin{tabular}{l|c|c|c}
\hline Variables & Dimensions & Mean & $\begin{array}{c}\text { Standard } \\
\text { Deviation }\end{array}$ \\
\hline \multirow{4}{*}{ Religious coping } & Religious activities & 18.36 & 3.62 \\
\cline { 2 - 4 } & $\begin{array}{c}\text { Negative feelings } \\
\text { towards God }\end{array}$ & 2.68 & 3.09 \\
\cline { 2 - 4 } & Benevolent appraisal & 18.32 & 3.71 \\
\cline { 2 - 4 } & $\begin{array}{c}\text { Passive religious } \\
\text { coping }\end{array}$ & 4.92 & 3.13 \\
\cline { 2 - 4 } & $\begin{array}{c}\text { Active religious } \\
\text { coping }\end{array}$ & 8.60 & 2.71 \\
\hline
\end{tabular}

${ }^{\mathrm{a}} \mathrm{N}=50$.

coping) were significantly and adversely related to psychological suffering (a dimension of perception of suffering) at the $99 \%$ confidence interval $(\mathrm{P}=0.01)$; however, religious activities (a dimension of religious coping) were not correlated with physical and existential-spiritual dimensions of suffering (dimensions of perception of suffering). In addition, none of the other dimensions of religious coping were significantly related to dimensions of perception of suffering (Table 4).

The results of stepwise regression analysis conducted to predict perception of suffering showed that only religious activities (a dimension of religious coping) predicted 0.09 of the variance in psychological suffering (a dimension of perception of suffering). Therefore, religious activities had a significant and diverse relationship with psychological suffering. Beta coefficients indicated that a unit of change in religious activities changed the psychological suffering about 0.34 (Table 5).

\section{Discussion}

In the current study, the results of the Pearson correlation coefficient indicated the correlation between religious activities and psychological suffering. Moreover, the 
Table 4. The Results of the Pearson Correlation Coefficient between Dimensions of Religious Coping and Dimensions of Perception of Suffering Among Study Subjects

\begin{tabular}{lccc}
\hline & & \multicolumn{2}{c}{ Correlation Coefficient } \\
\cline { 2 - 4 } Variables & Physical Suffering & Psychological Suffering & Existential/Spiritual Suffering \\
\hline Religious activities & -0.02 & $-0.34^{\mathrm{a}}$ & -0.05 \\
Negative feelings towards God & 0.09 & 0.13 & -0.01 \\
\hline Benevolent appraisal & -0.12 & -0.17 & -0.05 \\
Passive religious coping & -0.12 & 0.01 & -0.09 \\
\hline Active religious coping & 0.19 & -0.01 & -0.09 \\
\hline
\end{tabular}

${ }^{\mathrm{a}} \mathrm{P}<001$.

Table 5. The Results of Stepwise Regression Analysis Conducted to Predict Dimensions of Perception of Suffering among Study Subjects

\begin{tabular}{c|c|c|c|c|c|c|c}
\hline \multicolumn{2}{c|}{ Variables } & R & $\mathbf{R}^{2}$ & $\begin{array}{c}\text { Adjusted R } \\
\text { Square }\end{array}$ & Beta & F (df) \\
\hline $\begin{array}{c}\text { Predictor } \\
\begin{array}{c}\text { Religious } \\
\text { activities }\end{array}\end{array}$ & $\begin{array}{c}\text { Criterion } \\
\text { suffering }\end{array}$ & 0.34 & 0.11 & 0.09 & $-0.34^{\mathrm{a}}$ & -2.52 \\
\hline $\mathrm{a} P<0.001$ & & & & \\
\hline
\end{tabular}

${ }^{\mathrm{a}} \mathrm{P}<0.001$

results of stepwise regression analysis to predict perception of suffering demonstrated that only religious activities predicted psychological suffering.

The obtained results were in line with those of a study that revealed religion can provide a ground that facilitates the interpretation of a disease for patients (28). Additionally, another study showed that spirituality was associated with mental health and mental well-being and that it influenced coping strategies, attitudes and perceived meaning (29). Zeilani demonstrated that patients' religious beliefs and prayers, as religious activities, helped patients to experience lower levels of suffering. Religious-spiritual coping can be very helpful when dealing with chronic diseases (14). Several studies argued that people under stress often converted their general religious beliefs to specific coping strategies or problem-solving behaviors (22). Furthermore, they showed that religion and spirituality were associated with a decrease in the level of stress. A study conducted on patients with breast cancer indicated the importance of religious coping in improving the level of quality of life and found the significant influence of religious coping among patients with breast cancer (30). A longitudinal study demonstrated that promoting spiritual and religious aspects after diagnosing HIV infection can slow down the progression of the disease (31). In another study, it was concluded that positive religious coping was associated with more hope, psychological comfort and purpose in life and less psychotic symptoms (32). A study indicated that positive religious coping was correlated with an in- crease in the level of quality of life, health, mental and social health, and a decrease in the level of psychological distress symptoms (26). In Iran, Hasankhani conducted a study on chemical warfare veterans and mentioned that religious coping strategies were among positive and affective factors which influenced the endurance of pain and suffering caused by chemical injuries (27).

In the current study, the dimensions of the negative religious coping were not significantly related to the physical and existential-spiritual dimensions of perception of suffering. In spite of this result, a two-year longitudinal study, conducted on 268 elderly patients admitted to a hospital, revealed that negative religious coping methods had risky effects on patients' physical and mental health (29). Another study argued that individuals who expressed their anger towards God or questioned God were more anxious and their quality of life was negatively affected by their negative coping (33). Moreover, it was found that greater use of positive religious coping was associated with higher scores on the existential and support dimensions of quality of life, while greater use of negative religious coping was related to lower quality of life and increased risk of major depression and anxiety disorders $(31,34)$.

Furthermore, the results of the current study showed that the mean scores of patients undergoing dialysis on the physical and psychological dimensions of suffering were all lower than the mean score of the questionnaire; however, their mean score on the spiritual suffering was greater than the mean score of the questionnaire. More- 
over, the mean score of patients undergoing dialysis on the positive religious coping was higher than the mean score of the questionnaire and their mean score on the negative religious coping was lower than the mean score of the questionnaire.

Most studies confirmed the effect of the duration of dialysis on the severity and extent of mental health issues among patients undergoing dialysis. However, the results of some studies showed that although the physical functioning of patients with hard-treated chronic diseases reduced over time, their mental health status remained fairly stable. This may be due to the fact that patients consistently and effectively coped with the disease (35).

Therefore, the majority of patients considered spiritual suffering as an integral part of their lives and believed that the spiritual suffering made them aware of the existence of God and helped them to be grateful. This helped them to control their social functioning. It can be concluded that despite the problems and stressors that a patient dealt with during a treatment, he/she could explain, interpret and give a meaning to his/her suffering.

\subsection{Strengths and Limitations}

The main strengths of the current study were as follows: First, the study was conducted through applying regression methods which helped the authors to obtain casual results. The second strength of the study was its subjects. The subjects of the current study included patients undergoing dialysis and, to the authors' best knowledge, very few studies are conducted to examine suffering among this group of patients.

According to the results, it is recommended that institutes and centers that deal with patients undergoing dialysis pay more attention to these people's religious coping styles and present related trainings and cultural programs aimed to promote their positive religious coping.

Among the limitations of the current study the small sample size, unwillingness of some patients due to their poor physical and mental conditions and low literacy or illiteracy of some of the subjects (solved through reading the questionnaires to them) can be mentioned. Therefore, it is suggested that future studies should be conducted on larger samples, other variables influencing perception of suffering among patients undergoing dialysis and subjects with different cultural backgrounds and religious beliefs.

\section{Acknowledgments}

This article was derived from a master's thesis of general psychology approved by University of Sistan and Baluchestan. The authors greatly thank all the patients undergoing dialysis who helped to conduct the present study.

\section{References}

1. Narimani M, Rafigh Irani S. A survey of relationship between coping styles and mental health in patients undergoing hemodialytic treatment. Fundamentals of Mental Health. 2008;10(38):117-22.

2. de Ridder D, Schreurs K. Developing interventions for chronically ill patients: is coping a helpful concept?. Clin Psychol Rev. 2001;21(2):20540. [PubMed: 11293366].

3. Baloochi Beydokhti T, Kianmehr M, Tavakolizadeh J, BasiriMoghadam M, Biabani F. Effect of Muscle Relaxation on Hemodialysis Patients' Pain. Quarterly of the Horizon of Medical Sciences. 2015;21(2):75-80.

4. Nikmanesh Z, Askari N. The Role of Positive Affection on Predicting the Aspects of Pain Perception in MS Patients. J Res amp Health. 2014;4(1):570-4.

5. Aminoff BZ, Purits E, Noy S, Adunsky A. Measuring the suffering of end-stage dementia: reliability and validity of the Mini-Suffering State Examination. Arch Gerontol Geriatr. 2004;38(2):123-30. [PubMed: 14698490].

6. Ryrie I, Cornah D, Van de Weyer C. Food, mood and mental health. Ment Health Today. 2006:23-6. [PubMed: 16491737].

7. Kang KA, Im JI, Kim HS, Kim SJ, Song MK, Sim S. The Effect of Logotherapy on the Suffering, Finding Meaning, and Spiritual Well-being of Adolescents with Terminal Cancer.J Korean Acad Child Health Nursing. 2009;15(2):136. doi: 10.4094/jkachn.2009.15.2.136.

8. Barton-Burke M, Barreto RC, Archibald LI. Suffering as a multicultural cancer experience. Semin Oncol Nurs. 2008;24(4):229-36. doi 10.1016/j.soncn.2008.08.002. [PubMed:19000596].

9. Braam AW, Schrier AC, Tuinebreijer WC, Beekman AT, Dekker JJ, de Wit MA. Religious coping and depression in multicultural Amsterdam: a comparison between native Dutch citizens and Turkish, Moroccan and Surinamese/Antillean migrants. J Affect Disord. 2010;125(1-3):26978. doi: 10.1016/j.jad.2010.02.116. [PubMed: 20334926].

10. Krause N, Bastida E. Religion, suffering, and health among older Mexican Americans. J Aging Stud. 2009;23(2):114-23. doi: 10.1016/j.jaging.2008.11.002. [PubMed: 21415936].

11. Shahabizadeh F, Bahrainian AM. Causal model of spiritual Coping strategy in crisis, Parental Religiousness and Perceived Attachment Childhood. J Med Figh. 2013;5(15, 16):96-117.

12. Tykocki T, Kornakiewicz A, Mandat T, Nauman P. Pain perception in patients with Parkinson's disease. J Clin Neurosci. 2013;20(5):663-6 doi: 10.1016/j.jocn.2012.05.043. [PubMed: 23485408].

13. Karekla M, Constantinou M. Religious Coping and Cancer: Proposing an Acceptance and Commitment Therapy Approach. Cognitive and Behavioral Practice. 2010;17(4):371-81. doi:10.1016/j.cbpra.2009.08.003.

14. Zeilani R, Seymour JE. Muslim women's experiences of suffering in Jordanian intensive care units: a narrative study. Intensive Crit Care Nurs. 2010;26(3):175-84. doi:10.1016/j.iccn.2010.02.002. [PubMed: 20434344].

15. Ramirez SP, Macedo DS, Sales PM, Figueiredo SM, Daher EF, Araujo $\mathrm{SM}$, et al. The relationship between religious coping, psychological distress and quality of life in hemodialysis patients.J Psychosom Res. 2012;72(2):129-35. doi: 10.1016/j.jpsychores.2011.11.012. [PubMed: 22281454].

16. Dedeli O, Kaptan G. Spirituality and Religion in Pain and Pain Management. Health Psychol Res. 2013;1(3):154-9. doi:10.4081/hpr.2013.e29. [PubMed: 26973914].

17. Akbari B, Keshavarz Safei L, Deghan-Banadaki E. The relationship between of spiritual intelligence and happiness with the life quality of addict women who deserting in Rasht. Int Res J App Basic Sci. 2013;4(8):2272-6. 
18. Bentur N, Stark DY, Resnizky S, Symon Z. Coping strategies for existencial and spiritual suffering in Israeli patients with advanced cancer. Isr J Health Policy Res. 2014;3:21. doi: 10.1186/2045-4015-3-21. [PubMed: 24984840].

19. Beiranvand S, Noparast M, Eslamizade N, Saeedikia S. The effects of religion and spirituality on postoperative pain, hemodynamic functioning and anxiety after cesarean section. Acta Med Iran. 2014;52(12):909-15. [PubMed: 25530054].

20. Ursaru M, Crumpei I, Crumpei G. Quality of life and religions coping in women with breast cancer. Social and Behavioral Sciences. 2014;114:322-6.

21. Huang S, Han S. Shared beliefs enhance shared feelings: religious/irreligious identifications modulate empathic neural responses. Soc Neurosci. 2014;9(6):639-49. doi: 10.1080/17470919.2014.934396. [PubMed: 24963650].

22. Saltareli S, Raminelli-da-Silva Tde C, Castanho AC, Falconi-Gomez RR, Colhado OC, Faleiros-Sousa FA. The pain of existing and religion from the perspective of Catholics. Rev Lat Am Enfermagem. 2015;23(4):68592. doi: 10.1590/0104-1169.0188.2604. [PubMed: 26444171]

23. Salehi I, Mosalman M. Evaluation of the Relationship between Religious Attitude and Depression, Anxiety and Stress in Students of Guilan University. Religion Health. 2015;3(1):57-64.

24. Schulz R, Monin JK, Czaja SJ, Lingler JH, Beach SR, Martire LM, et al. Measuring the experience and perception of suffering. Gerontologist. 2010;50(6):774-84. doi: 10.1093/geront/gnq033. [PubMed: 20478899].

25. Nikmanesh Z, Pirasteh Motlagh AA, Akbari Ali Abad T. The Relationship of Spirituality and Awareness and Attitude towards Disease with Feeling of Suffering in Patients with AIDS/HIV. J Res Psychol Health. 2014;8(2):44-57.

26. Aflakseir A, Coleman PG. Initial Development of the Iranian Religious Coping Scale. J Muslim Mental Health. 2011;6(1):44-61. doi: 10.3998/jmmh.10381607.0006.104.

27. Parandeh khozani L. Examine the relationship between religious cop- ing with stress, anxiety, depression and quality of life of mothers of children with defective hearing Master's thesis. Sistan and Baluchestan: University of Sistan and Baluchestan; 2011.

28. Seidmahmoodi J, Rahimi C, Mohamadi N. Resiliency and religious orientation: factors contributing to posttraumatic growth in Iranian subjects. Iran J Psychiatry. 2011;6(4):145-50. [PubMed: 22952540].

29. BonabGhobary B, Hakimirad H, Habibi H. Relation between mental health and spirituality in Tehran University student. Procedia - Social and Behavioral Sciences. 2010;5:887-91. doi: 10.1016/j.sbspro.2010.07.204.

30. Pargament KI, Koenig HG, Tarakeshwar N, Hahn J. Religious coping methods as predictors of psychological, physical and spiritual outcomes among medically ill elderly patients: a twoyear longitudinal study. J Health Psychol. 2004;9(6):713-30. doi: 10.1177/1359105304045366. [PubMed: 15367751].

31. Pearce MJ, Singer JL, Prigerson HG. Religious coping among caregivers of terminally ill cancer patients: main effects and psychosocial mediators. J Health Psychol. 2006;11(5):743-59. doi: 10.1177/1359105306066629. [PubMed: 16908470].

32. Rosmarin DH, Bigda-Peyton JS, Ongur D, Pargament KI, BjOrgvinsson T. Religious coping among psychotic patients: Relevance to suicidality and treatment outcomes. Psychiatry Res. 2013;210(1):182-7.

33. Hills J, Paice JA, Cameron JR, Shott S. Spirituality and distress in palliative care consultation. J Palliat Med. 2005;8(4):782-8. doi: 10.1089/jpm.2005.8.782. [PubMed:16128652].

34. Tarakeshwar N, Vanderwerker LC, Paulk E, Pearce MJ, Kasl SV, Prigerson HG. Religious coping is associated with the quality of life of patients with advanced cancer. J Palliat Med. 2006;9(3):646-57. doi: 10.1089/jpm.2006.9.646. [PubMed: 16752970].

35. Navidian A, Arbabi Sarjou A, Kikhai A. Frequency of Mental Disturbances in Hemodialysis Referred to Hemodialysis Ward of KhatamAl-anbia Hospital in Zahedan. J Guilan Univ Med Sci. 2006;15(58):6-67. 